DISTRIBUTION STATEMENT A. Approved for public release; distribution is unlimited.

\title{
Forecasting Future Sea Ice Conditions: A Lagrangian Approach
}

\author{
Bruno Tremblay \\ Lamont-Doherty Earth Observatory of Columbia University \\ phone: (514) 398-4369 fax: (514) 398-6115 email: bruno.tremblay@columbia.edu \\ Award Number: N000141110977 \\ http://brunotremblayseaice.jimdo.com \\ http://extranet.nsidc.org/IceMotion/
}

\section{LONG-TERM GOALS}

1- Show from observations whether the dynamics of the multi-year pack ice has a key influence on the location of the following summer MIZ.

2- Determine the source regions of summer sea ice in coastal zones using a back trajectory model forced with satellite-derived sea-ice drift (Maslanik et al. 1995, Emery et al. 1997, Meier et al. 2000, Tschudi et al. 2010)

3- Assess whether the source region of sea ice melting in peripheral seas in the GCMs participating in IPCC AR5 agree with observed source region patterns from the satellite-derived dataset.

4- Compare Lagrangian ice trajectories in the model with satellite datasets.

5- Repeat this comparative analysis for three critical climate horizons: a base period with a dominant perennial sea ice cover and two projection periods in the $21^{\text {st }}$ Century (2040-2060 and 20802080).

\section{OBJECTIVES}

1- Reduce uncertainties in future sea ice extent prediction from climate models participating in CMIP5. These include temporal evolution and geographical distribution of sea ice cover and transport pathways.

2- Improve our understanding of the strengths and/or limitations of GCM predictions of future ice edge positions.

3- Identify limitations in the ability of GCMs to simulate source regions for sea ice being advected into marginal ice zones (MIZs) and thus provide guidance for developing more reliable forecasts of the future evolution of transports of material between remote areas of the Arctic.

4- Quantify GCM biases in the balance of thermodynamically formed, in situ, ice production as opposed to advection gain and loss.

5- Develop a seasonal forecast model for sea ice extent using satellite-derived ice concentrations, PIOMAS ice thickness, RGPS ice deformation, Reanalysis atmospheric data and Lagrangian seaice back trajectories to estimate thermodynamic and dynamic (advection) ice loss. 


\section{Report Documentation Page}

Form Approved

OMB No. 0704-0188

Public reporting burden for the collection of information is estimated to average 1 hour per response, including the time for reviewing instructions, searching existing data sources, gathering and maintaining the data needed, and completing and reviewing the collection of information. Send comments regarding this burden estimate or any other aspect of this collection of information,

including suggestions for reducing this burden, to Washington Headquarters Services, Directorate for Information Operations and Reports, 1215 Jefferson Davis Highway, Suite 1204, Arlington

VA 22202-4302. Respondents should be aware that notwithstanding any other provision of law, no person shall be subject to a penalty for failing to comply with a collection of information if it

does not display a currently valid OMB control number.

1. REPORT DATE

30 SEP 2014

4. TITLE AND SUBTITLE

Forecasting Future Sea Ice Conditions: A Lagrangian Approach

6. $\operatorname{AUTHOR}(\mathrm{S})$

7. PERFORMING ORGANIZATION NAME(S) AND ADDRESS(ES)

Lamont-Doherty Earth Observatory of Columbia University,61 Route 9w,Palisades,NY,10964

9. SPONSORING/MONITORING AGENCY NAME(S) AND ADDRESS(ES)

3. DATES COVERED

00-00-2014 to 00-00-2014

5a. CONTRACT NUMBER

5b. GRANT NUMBER

5c. PROGRAM ELEMENT NUMBER

5d. PROJECT NUMBER

5e. TASK NUMBER

5f. WORK UNIT NUMBER

8. PERFORMING ORGANIZATION

REPORT NUMBER

10. SPONSOR/MONITOR'S ACRONYM(S)

11. SPONSOR/MONITOR'S REPORT

$\operatorname{NUMBER}(S)$

12. DISTRIBUTION/AVAILABILITY STATEMENT

Approved for public release; distribution unlimited

13. SUPPLEMENTARY NOTES

14. ABSTRACT

15. SUBJECT TERMS

16. SECURITY CLASSIFICATION OF:

a. REPORT

unclassified b. ABSTRACT

unclassified c. THIS PAGE

unclassified
17. LIMITATION OF ABSTRACT

Same as

Report (SAR)
18. NUMBER 19a. NAME OF

OF PAGES RESPONSIBLE PERSON

5 


\section{APPROACH}

We use a Lagrangian trajectory model to track the dynamics of the multi-year and first year ice boundary. To this end, we are able to identify the source regions for sea ice that melts and sea ice that survives the summer melt season in each of the Arctic peripheral seas. The Lagrangian Model is forced with weekly mean satellite-derived sea-ice drifts, and monthly- or daily-mean sea-ice drift from the Coupled Model Intercomparison Project 5 (CMIP5) GCMs. The ice-motion vectors come from the NSIDC's CDR (Climate Data Record) product, which is derived using brightness temperatures from passive microwave radiometers (SSM/I, SSMIS, SSMR, AVHRR, AMSRE) using a combination of the bootstrap and NASA-Team algorithm (Fowler et al, 20??). The CDR data product also assimilates buoy data when present within a radius of a few hundred kilometers. In the summer, when the crosscorrelation algorithm between brightness temperature images has difficulties identifying features on the ice surface, the data set relies on both buoy data and free-drift estimates, the latter derived from reanalysis of sea level pressure data.

\section{WORK COMPLETED}

The Lagrangian trajectory model forced with satellite-derived or GCMs sea-ice drift data is completed. The model is also being used by two students involved in the project: Patricia de Repentigny (Masters student) and James Williams (PhD student) working on long-term and seasonal forecasting of Arctic sea ice respctively.

The analysis of the total thermodynamic and dynamic sea ice loss for the instrumental record is completed. We define thermodynamic loss as sea ice loss resulting from basal melting via ocean heat flux, or surface melting via radiative/turbulent losses. We define dynamic loss as summer sea ice extent loss via sea ice export through Fram Strait (mainly) or sea ice extent loss via convergence of the pack ice within the Artic Ocean proper.

The quantification of dynamical pre-conditionning via advection of the multi-year pack ice is complete. We define dynamical pre-conditioning as the motion of the multi-year pack ice away from coastlines of the peripheral seas of the Arctic Ocean. This can be accomplished via multi-year sea-ice export through Fram Strait (mainly) or (since the mid-nineties) through convegence of the multi-year pack ice within the Arctic Ocean proper.

Analysis of all factors responsible for the loss of summer sea ice (or the sea-ice extent minimum) is complete. These include, multi-year ice advective flux away from coastlines in winter, Bering Strait heat inflow and basal ice loss, and surface melt during the summer via radiative/turbulent fluxes.

We have added features to the Ice Tracker program originally developed by Chuck Fowler at University of Colorado (not publicly available). The new Ice Tracker will be hosted on the http://thepolarhub.org/ web site based at columbia University that was developed under a separate PoLAR initiative funded by the National Science Foundation (PI: Pfirman). The Ice Tracker is an online program that allows users to plot the trajectory of a sea ice floe (backward or forward in time) starting from any ice covered area in the Arctic Ocean within the satellite era (1979-2013). The new Ice Tracker allows the user to select multiple trajectories, and to overlay other fields (air temperature, ice age, ice thickness, etc) on the Lagragian trajectories. The data can also be saved for analysis. This tool is useful for a wide variety of applications including sediment, nutrient and pollutant transport by 
sea ice, seasonal forecasts, rescue, emergency response, educational purposes, etc. The site is also available on the National Snow and Ice Data Center http://extranet.nsidc.org/IceMotion/.

\section{RESULTS}

The project comprises three parts: 1- establishing the link, from observations, between the dynamic of the multi-year ice pack in winter and the following summer sea-ice extent, with a particular emphasis on the minimum sea-ice extent, 2- identifying the source regions for multi-year sea ice surviving the melt season in each of the Arctic peripheral seas for today's climate and for future climate as simulated by General Circulation models, and 3- comparing the source region and MIZ dynamics simulated by GCMs and observed using the instrumental record.

Results from Part 1 show a clear correlation $(\mathrm{r} 2=-0.72)$ between the state of the previous winter (Dec-Jan-Feb-Mar) large scale atmospheric circulation (characterized here by the Arctic Oscillation AO) and the following summer minimum sea ice extent since 1993 when the sea ice thickness in the Arctic appear to have reached a critical value for winter pre-conditioning to have an impact on the following summer ice extent (see Figure 1). A positive AO index also correlates with sea ice export through Fram Strait, and winter surface air temperature and sea ice concentration anomaly in the Western Beaufort, Chukchi and Eurasian Seas. The dynamic and thermodynamic effects on the location of the MIZ are strongly coupled. In fact southerly winds advect the (multi-year) ice pack away from coastlines but also advect warm air northward, limiting ice growth in the winter and favoring melt in the summer. Our preliminary results using backward Lagrangian trajectories of sea ice suggest that the dynamics (ice motion) in winter is at least equally responsible for anomalous sea ice extent and position of the MIZ as thermodynamic effect. Results also show a strong correlation $(r=0.8)$ between the Bering Strait heat inflow and sea ice concentration in the Chukchi Sea region. In fact, it explains $30 \%$ of the variance in the residual signal not explained by the AO. These results clearly point at the importance of the dynamics of the multi-year pack ice in the previous winter on the following summer sea ice conditions. This is in accord with results from Feltham et al. (2014) who showed a high correlation between the first year ice extent prior to the melt season (May and particularly June) and the minimum sea ice extent. Our analyses show that the previous winter atmospheric circulation in turns defines the extent of the first ice extent in May/June. This effectively extends the seasonal forecast period by 3 months (end of March as opposed to June).

During the backward Lagrangian trajectory analysis, we identified a significant positive bias between the background satellite-derived CDR dataset and buoy drift data (with buoy drift being faster by several $\mathrm{cm} / \mathrm{sec}$; see Figure 2). This results in a trend in the mean Arctic sea ice drift that is much larger than previously reported in the literature using ice buoys alone. This trend is in part the result of the increasing number of buoys assimilated in the satellite derived drift product as time progresses from 1979 to the present. We are presently analyzing the three parent data sets used in the construction of the CDR satellite-derived drift product in an attempt to eliminate this bias. The presence of this bias can potentially have important consequences. The CDR dataset is used to derive the ice-age data product of (Fowler et al., 2004). An artificial trend in ice drift speed, will lead to an exaggerated temporal trend in the loss of older ice in the Arctic. The CDR dataset is also used by ice-ocean modeling groups for instance to calibrate/validate their ice thickness redistribution scheme (e.g. Hunke, 2014). An unforeseen goal of our work is to now re-process the three drift constituents to the CDR dataset, eliminating this bias, in order to resume the back trajectory work for the instrumental record time period on a firmer basis. 
In preparation for the Lagrangian back-trajectory work using GCMs, we have run back and forward trajectories using code developed in the course of this proposal and 12-hourly buoy data from the International Arctic Buoy Program. The results show that the use of weekly average sea-ice drift data to calculate the back-trajectories lead to relatively small error $(150 \mathrm{~km}$ for a total drift distance of $25000 \mathrm{~km}$ ) even for sea-ice drifts of more than 2-year. We are now repeating the analysis using monthly mean sea ice drift - typically saved by GCM modeling group participating in CMIP5). Depending on the error statistics using monthly mean drift data, we will use the daily or monthly drift speed from the GCM to drive the Lagrangian code and map the regions for the multi-year ice surviving the summer melt in each of the Arctic peripheral seas in todays climate and the transitional period to a summer ice free Arctic (2040-2060) and a virtually ice-free Arctic (2080-2100).

\section{IMPACT/APPLICATIONS}

The CDR ice drift vectors and its companion data set, the ice age data, are widely used in the community for model validation and Arctic climate change assessment. The re-processing of this dataset will eliminate potential errors associated with a bias in the satellite-derived sea ice drift when compared with the buoy data.

The Lagrangian trajectory model allow for a clear attribution of summer sea ice loss between dynamic preconditionning of the system in the winter and dynamic versus thermodynamic effect during the summer.

The IceTracker is now publicly available. This new tool will be publicly available online shortly. It can be used for education, environmental, and scientific purposes. See Work Completed section for details. Impact: see http://blogs.ei.columbia.edu/2013/12/10/explore-the-arctic-ocean-with-icetracker/

\section{RELATED PROJECTS}

See last year for complete list.

Energy dissipation in viscous-plastic sea-ice models: In viscous-plastic (VP) sea-ice models, small deformations are approximated by irreversible viscous deformations, introducing a nonphysical energy sink. As the spatial resolution and the degree of numerical convergence of the models increase, linear kinematic features (LKFs) are better resolved and more states of stress lie in the viscous regime. Energy dissipation in this nonphysical viscous regime therefore increases. We derive a complete kinetic energy (KE) balance for sea ice, including plastic and viscous energy sinks to study energy dissipation. The main KE balance is between the energy input by the wind and the dissipation by the water drag and the internal stresses (dissipating $87 \%$ and $13 \%$ of the energy input on an annual average). The internal stress term is mostly important in winter when ice-ice interactions are dominant. The energy input that is not dissipated locally is redistributed laterally by the internal stresses into regions of dissipation by small-scale deformations (LKFs). Of the $13 \%$ dissipated annually by the internal stress term, 93\% is dissipated in plastic friction along LKFs (14\% in ridging, 79\% in shearing) and $7 \%$ is stored as potential energy in ridges. For all time and spatial scales tested, the frictional viscous dissipation is negligible in the KE balance. This conclusion remains valid regardless of the degree of numerical convergence of the simulations. Overall, the results confirm the applicability, from an energetical point of view, of the VP approximation. 


\section{REFERENCES}

Emery, W., C. Fowler and J. Maslanik, 2012, Satellite-derived maps of Arctic and Antarctic sea ice motion: 1988 to 1994, Geophysical Research Letters, DOI: 10.1029/97GL00755.

Fowler, C., W. Emery, and M. Tschudi. 2013. Polar Pathfinder Daily $25 \mathrm{~km}$ EASE-Grid Sea Ice Motion Vectors. Version 2. Boulder, Colorado USA: National Snow and Ice Data Center.

Maslanik, J.A., Fowler, C., Heinrichs, J., Barry, R.G., and Emery, W.J., "Remotely-sensed and simulated variability of Arctic sea-ice concentrations in response to atmospheric synoptic systems", International Journal of Remote Sensing, 16(17), 3325-3342, 1995

Meier, W.N., J.A. Maslanik, and C.W. Fowler, 2000. Error analysis and assimilation of remotely sensed ice motion within an Arctic sea ice model, Journal of Geophysical Reearch, 105(C2), 3339-3356.

Tschudi M., Fowler C., Maslanik J.A., Stroeve J, "Tracking the Movement and Changing Surface Characteristics of Arctic Sea Ice." IEEE Journal of selected topics in applied earth observations and remote sensing, 3(4), 536-540, 2010.

\section{PUBLICATIONS}

Dupont, F., M. Vancopenolle, B. Tremblay, "Comparison of different numerical approaches to the 1D problem of the sea-ice thermodynamics", Journal of Geophysical Research, [accepted for publication; refereed].

Sirven, J., L.B. Tremblay, “ Analytical study of an isotropic visco-plastic sea ice model in idealized configurations", Journal of Physical Oceanography, [in press; refereed].

Schmidt, G. A., Annan, J. D., Bartlein, P. J., Cook, B. I., Guilyardi, E., Hargreaves, J. C., Harrison, S. P., Kageyama, M., LeGrande, A. N., Konecky, B., Lovejoy, S., Mann, M. E., Masson-Delmotte, V., Risi, C., Thompson, D., Timmermann, A., Tremblay, L.-B., and Yiou, P., 2014: Using palaeo-climate comparisons to constrain future projections in CMIP5, Climate of the Past, 10, 221-250, doi:10.5194/cp-10-221-2014, [published, refereed].

Melissa Gervais, L. Bruno Tremblay, John R. Gyakum, Eyad Atallah. 2014: Representing Extremes in a Daily Gridded Precipitation Analysis over the United States: Impacts of Station Density, Resolution, and Gridding Methods. Journal of Climate, 27:14, 5201-5218. doi: http://dx.doi.org/10.1175/JCLI-D-13-00319.1, [published, refereed].

Melissa Gervais, John R. Gyakum, Eyad Atallah, L. Bruno Tremblay, and Richard B. Neale, 2014: How Well Are the Distribution and Extreme Values of Daily Precipitation over North America Represented in the Community Climate System Model? A Comparison to Reanalysis, Satellite, and Gridded Station Data. J. Climate, 27, 5219-5239. doi: http://dx.doi.org/10.1175/JCLI-D-1300320.1, [published, refereed].

Bouchat, A., L.B. Tremblay, “ Energy dissipation in viscous-plastic sea-ice models”, Journal of Geophysical Research - Oceans, 119, doi:10.1002/2013JC009436, 2014 [published, refereed]. 